\title{
Assessing Wind Impact on Noise Level Measurements for Application in Architectural Acoustics: A Preliminary Study
}

\author{
Ocholi M., ${ }^{1, *}$ Ibe K. E., ${ }^{1}$ Iheonu E. E. ${ }^{2}$ and Ameh E. E. ${ }^{1}$ \\ ${ }^{1}$ Science Laboratory and Technology Research Department, Nigerian Building and Road Research Institute, Km \\ 10, Idiroko Road, P.M.B 1055, Ota, Ogun State, Nigeria \\ ${ }^{2}$ Department of Physics, Lagos State University, Lagos-Badagry Expressway, Ojo, Lagos State, Nigeria \\ Corresponding Author: *mamuduocholi@nbrri.gov.ng
}

https://doi.org/10.36263/nijest.2021.02.0290

\begin{abstract}
In this study, we have used wind data obtained from an earlier work covering several locations in Nigeria to estimate the possible impact of wind on sound pressure levels. Estimated Weibull parameters were used to compute the most probable wind speed, the average wind speed and the duration for which wind speed exceeds or equal the most probable speed. Adopting the proposed criteria that wind is able to strengthen or weaken sound pressure levels by $3 d B$ depending on wind direction, the effect of wind on sound pressure level was determined. Results showed that wind effect seemed more predominant for the sub-sahelian stations such as Sokoto, Kano, and Maiduguri where the impact was found to be +/- $3 \mathrm{~dB}$ obviously due to the characteristic high wind speeds recorded at those stations. The situation is almost the same for the midland region except that moderate impacts were found in some of the stations like Yola, Yelwa and Bauchi. However, moderate wind impacts generally characterize the Guinea Savannah and the coastal regions with the exception of Enugu with an impact of +/- 3dB. The result for Warri was found to be insignificant. It was concluded that most locations within the Nigerian environment may attain the wind conditions that would necessitate an adjustment in noise level measurements for application in architectural acoustics. In order to further validate the results of this preliminary study, it was recommended that detailed field survey where all relevant parameters such as wind speeds, wind directions and noise levels are simultaneously measured be conducted.
\end{abstract}

Keywords: Sound Pressure Level, Wind, Environmental Noise, Architectural Acoustics, Noise Measurement

\subsection{Introduction}

Environmental noise as a polluting agent poses significant threat to the quality of life in most industrialized and industrializing nations (Ovenden et al., 2009; Srimanta and Chitralekha, 2011). In developing countries such as Nigeria, noise pollution is never considered to be a dangerous phenomenon with the associated adverse effect on the life of people especially in urban dwellings where it is usually predominant in view of the obvious societal lifestyle which tend to promote a noisy environment (Ighoroje et al., 2004; Abam and Unwachukwu, 2009). This is due to the fact that in many cases the harmful effect of noise pollution is not easily seen until after a considerable period of time. This probably explains why little effort is seen in the enforcement of noise pollution control laws in many parts of the country (Seidler et al., 2016; Gilani and Mir, 2021).

It has however been long accepted that road traffic noise constitutes the largest proportion of environmental noise in urban areas (Onuu and Menkiti, 1996; Onuu, 1999). Traffic noise may impact people in different ways such as impaired communication and interrupting sleep. Studies have shown that noise can contribute to an increased risk of cardio-vascular diseases (Babisch et al., 2005). The socio-economic costs associated with traffic noise have been calculated to be enormous (Road Noise Group, 2003). Consequently, the issue of environmental noise as it affects building acoustics is being considered as the focus of activity, both in encouraging research and promoting its practical applications. The acoustical environment of practically any architectural space ought to be evaluated 
in advance so as to provide an objective basis for the design of acoustically sound dwellings that combines both remedial and preemptive solutions to the problem of noise (Designing Buildings Wiki, 2021). Noise analysts frequently employ highway traffic noise models to predict existing and future highway noise levels, with and without noise barriers for adjacent receivers (TeNS, 1998). Whenever possible, model results are compared to measurements and calibrated if necessary. The purpose of model calibration is to account for certain conditions that cannot be accounted for by the model. Technical Noise Supplement (TeNS) 1998 defines model calibration as the process of adjusting calculated future noise levels by algebraically adding a calibration constant derived from the difference between measured and calculated noise levels at representative sites. Several site conditions that cannot be accounted for by noise model, even though they affect the noise environment and yet often ignored include, but are not necessarily limited to the following (Rudolf, 2003; Ovenden et al., 2009): (i) Atypical vehicle noise populations (ii) Pavement surface type and condition (iii) Meteorological conditions (iv) Transparent shielding (v) Reflections off nearby buildings and structures.

Existing prediction models calculate noise levels without considering atmospheric conditions such as wind velocities, and temperature profiles (Hadi Baaji et al., 2001; Steele, 2001; Lihoreau et al., 2006; Wayson et al., 1995; Ovenden et al., 2009; Towseef and Mohammad, 2021; Ramakrishna et al., 2021). Thus, zero winds and neutral temperature gradients are usually assumed. This is of course a reasonable assumption for shorter (less than $200 \mathrm{~m}$ ) distances from the sound source, but errors can be substantial when predicting intermediate and far-field noise, since refraction of sound due to temperature and wind causes anomalous intensity variations at a significant distance from the source (Ovenden et al., 2009). As observed by Rudolf (2003), the fact however is that noise measurements are normally made under varying atmospheric conditions. The same traffic volumes, truck mixes and speeds sometimes yield varying noise levels even at receivers near a highway, depending on the meteorological variables. It is therefore highly desirable to normalize and adjust noise measurements to neutral conditions, before the model is compared with and adjusted to the measurements. This way, we could arrive at more refined noise measurements which also lead to increased model calibration accuracy.

In this paper, we propose an adaptation of a formulation given by Diamant (1986) to selected locations within the Nigerian environment for design of acoustically sound architecture taking into consideration the effect of wind conditions. The primary objective is to assess wind impact on noise level measurements within the Nigerian environment and to provide a quantitative basis for normalization of noise level measurements to neutral wind condition.

\subsection{Methodology}

The wind data for this study was basically drawn from an earlier work (see Ocholi and Iheonu, 2011) but extending the wind speed applicability to noise propagation. Ocholi and Iheonu (2011) showed from the analysis of hourly wind data for 1991 through 1995 obtained from the Nigerian Meteorological Agency (NIMET), Oshodi that wind characteristics over Nigeria can be adequately monitored using the Weibull distribution function. The study employed the estimated Weibull parameters to compute the most probable wind speed $V_{m p}$, the average wind speed $V_{c, k}$ and the duration $T$ for which wind speed exceeds or equal the most probable speed.

Following Diamant (1986) and the results of a more recent work of Trikootam and Hornikx (2019), a wind speed of $5 \mathrm{~ms}^{-1}$ can either increase or decrease the sound pressure level by $3 \mathrm{~dB}$, while the effect of winds weaker or stronger than a speed of $5 \mathrm{~ms}^{-1}$ on sound pressure level may be expressed logarithmically as:

$\Delta d B=3+\log \frac{V}{5}$

Where $V$ is the actual wind speed (in $\mathrm{ms}^{-1}$ ) at the study location. The effect of wind on sound pressure level can be calculated using Eq. (1) and the results obtained by Ocholi and Iheonu (2011) for the most probable wind speeds $V_{m p}$ at 2 meters height above the ground surface which has been reproduced here in Table 1. 
Table 1: The most probable wind speed $V_{m p}$ at 2 meters height above the ground surface for all the study stations reproduced from Ocholi and Iheonu (2011).

\begin{tabular}{lllll}
\hline Station & Lat. $\left({ }^{\circ} \mathrm{N}\right)$ & Long. $\left({ }^{\circ} \mathrm{E}\right)$ & Alt. $(\mathrm{m})$ & $V_{m p}\left(\mathrm{~ms}^{-1}\right)$ \\
\hline Sokoto & 13.02 & 5.25 & 350 & 2.27 \\
Kano & 12.05 & 8.53 & 472 & 4.56 \\
Maiduguri & 11.85 & 13.08 & 353 & 1.78 \\
Yelwa & 10.83 & 4.73 & 142 & 0.85 \\
Bauchi & 10.37 & 9.80 & 666 & 0.71 \\
Minna & 9.62 & 6.53 & 258 & 2.45 \\
Jos* & 9.58 & 8.95 & 1219 & 5.92 \\
Yola & 9.23 & 12.47 & 186 & 0.24 \\
Ibi & 8.18 & 9.75 & 110 & 1.68 \\
Oshogbo & 7.80 & 7.03 & 300 & 1.11 \\
Lokoja & 7.78 & 6.74 & 151 & 0.31 \\
Ibadan & 7.43 & 3.70 & 227 & 1.34 \\
Ikeja & 6.58 & 3.33 & 39 & 0.70 \\
Enugu & 6.47 & 7.55 & 141 & 2.49 \\
Warri & 5.52 & 5.73 & 6 & 0.14 \\
Uyo & 5.05 & 7.93 & 188 & 1.14 \\
\hline \multicolumn{5}{c}{} \\
\hline
\end{tabular}

An examination of the data reveals that wind speed records for all the stations are characteristically higher between the hours of 6.00 and 18.00 whereas generally lower outside this period of the day (see Figure 1).

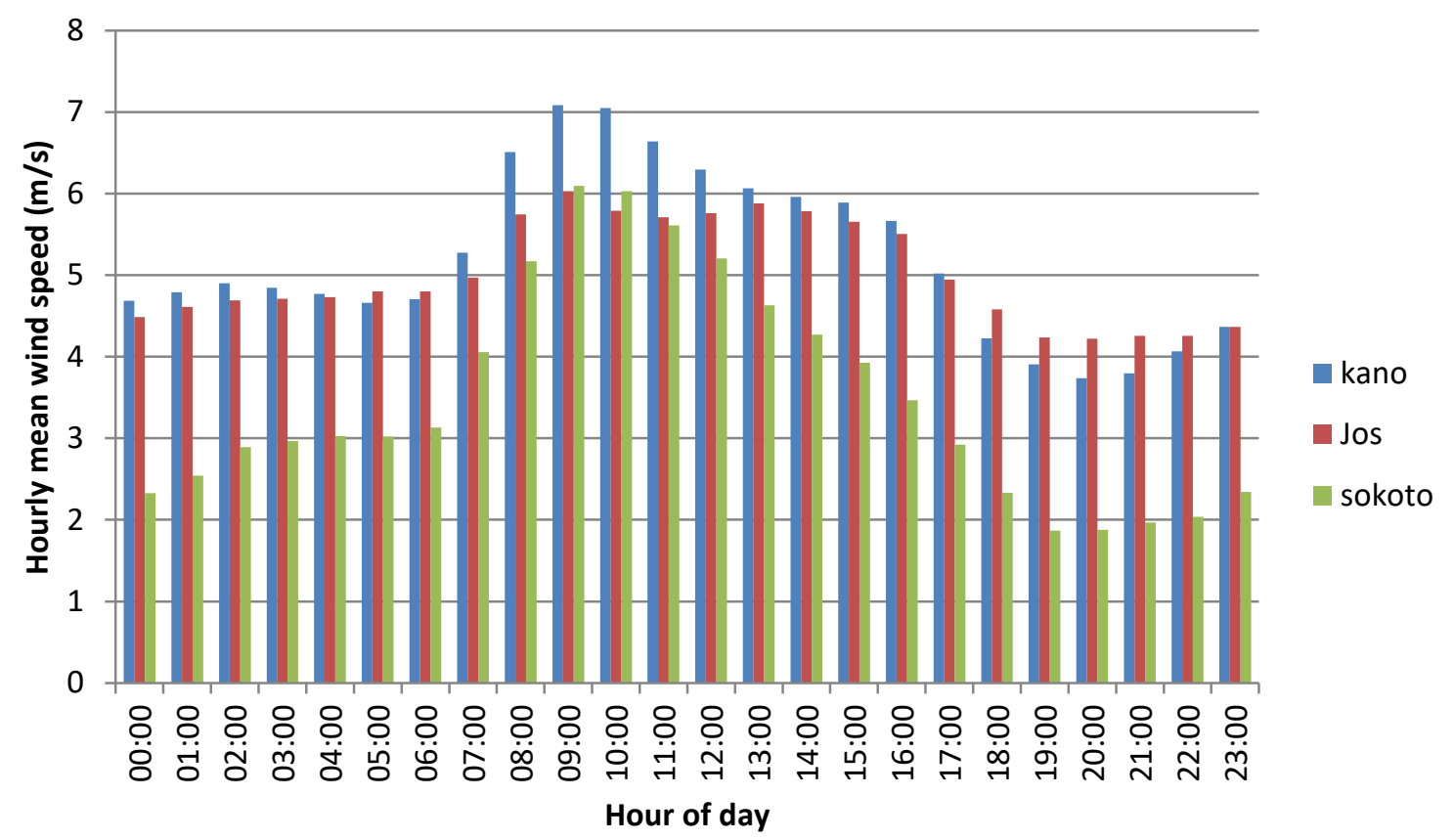

Figure 1: Hourly mean wind speed characteristics over 24 hours period of the day shown for three of the stations studied (Kano, Jos and Sokoto).

It is therefore appropriate to evaluate the impact within this period of the day and to be compared with those for the whole day. Consequently, in addition to utilizing the entire data, the wind data falling between 6.00 and 18.00 hours were used in the computation of the most probable wind speed $V_{m p}$. The results obtained were employed in Eq. (1) to estimate sound pressure level increase or reduction at each station depending on the prevailing wind direction. Following Ocholi and Iheonu (2011), the most probable wind speed $V_{m p}$ is given by:

$V_{m p}=c\left(\frac{k-1}{k}\right)^{\frac{1}{k}}$ 
where $k$ (dimensionless) and $c$ (in $\mathrm{m} / \mathrm{s}$ ) are the Weibull's shape and scale parameters respectively which can be easily estimated by fitting the empirical data $v$ to the Weibull's cumulative distribution function $p(v)$ given by:

$p(v)=1-\exp \left[-\left(\frac{v}{c}\right)^{k}\right]$

Details of the procedure for the computations are given by Ocholi and Iheonu (2011) and Ishwar and Bhargava (1985). In this study, a code was written in MATLAB to compute the values for $\Delta d B$ and $V_{m p}$ for all the stations studied in earlier work and also for Jos at 2 meters height above the earth surface (see Appendix).

Normally, in applying these results to account for the effect of wind on sound pressure levels at certain distance from the traffic line, the orientation of the highway (i.e. the source of noise) relative to the prevailing wind direction of the area must be taken into consideration to compute the cross wind components (CWC's). The cross wind component is that component of the wind that is at 90 degrees to the highway. There is a direct relationship between the CWC's and the wind speeds and directions. For a given site, the change in noise levels due to atmospheric conditions can for a significant part be explained by CWC's (Rudolf, 2003). Assuming that road traffic is perpendicular to wind flow, the wind impacts determined from CWC's is essentially the same as those computed from measured wind velocities (i.e. speeds and directions). For the purpose of this preliminary study, we have assumed here that the highways are perpendicularly positioned relative to wind direction at all the stations.

\subsection{Results and Discussion}

Presented in Table 2 is the result quantifying the effect that the wind condition could have on sound pressure level measurements over two periods of time (i.e. 24 hours and day time between 6.00 to 18.00 hours) at the study stations. It was observed that for both periods, the biggest effect of $+/-3 \mathrm{~dB}$ is seen at 7 out of the 16 stations that were studied. The stations include Enugu, Ibi, Maiduguri, Minna, Kano, Sokoto and Jos. Other stations produced an impact of $+/-2 \mathrm{~dB}$ on their sound pressure levels for both periods except at Warri where the impact dropped to $+/-1 \mathrm{~dB}$ for calculations made over the 24 hours period. This observation tends to suggest that the wind impact at all the study stations except Warri is not dependent on the period of the day. Hence, we expect to see an adjustment (addition or subtraction) in noise level measurements that is equal in proportion with the calculated impacts. It is interesting to note that wind poses significant effect on sound pressure levels at all the stations studied with probable exception of Warri where the impact calculated over 24 hours seemed insignificant (Müller and Möser, 2013 ). The effect however seemed more predominant for the sub-sahelian stations such as Sokoto, Kano, and Maiduguri where the impact was found to be $+/-3 \mathrm{~dB}$. This is obviously due to the characteristic high wind speeds recorded at those stations. The situation is almost the same for the midland region except that moderate impacts were found in some of the stations like Yola, Yelwa, and Bauchi. However, moderate wind impacts generally characterize the Guinea Savannah and the coastal regions with the exception of Enugu with an impact of $+/-3 \mathrm{~dB}$. Overall, this observation may signal the need for a more detailed assessment of wind impact on noise level measurements at those stations for improved acoustical design of noise abatement.

It should be cautioned at this point that this work only presents the result of a preliminary investigation of wind impact on noise measurements and as such may not necessarily reflect the actual situation for several reasons. First, the data employed in this study were derived for 2 meters height from data measured at standard height of 10 meters above the ground surface. Second, measurements were taken at airport areas and as such local conditions for locations remote from the airports may vary considerably. Studies have shown that wind effects on noise levels are affected by the presence or absence of a noise barrier and also on the distance from the highway (Rudolf, 1991; Ovenden et al 2009). Furthermore, the assumption that highways are perpendicularly aligned with respect to wind direction may not be met in most cases. Hence, it suffices to say that detailed field measurements of relevant parameters such as wind velocities and noise levels be carried out simultaneously on site at the desired distance from the road and at the appropriate height above the ground surface for an impact assessment that is more reflective of specific site peculiarities. 
Table 2: Calculated impact of wind condition on sound pressure level measurements; based on data covering 24 hours of the day and for Day time (6.00 to 18.00 hours, Local Time) at the study stations

\begin{tabular}{lllllll}
\hline Station & \multicolumn{2}{l}{ Geographic Location } & & Alt. $(\mathrm{m})$ & $+\Delta$ dB & \\
& Lat. $\left({ }^{\circ} \mathrm{N}\right)$ & Long. $\left({ }^{\circ} \mathrm{E}\right)$ & Region & & 24 Hours & Day time \\
\hline Sokoto & 13.02 & 5.25 & Sub-Sahel & 350 & 3 & 3 \\
Kano & 12.05 & 8.53 & & 472 & 3 & 3 \\
Maiduguri & 11.85 & 13.08 & & 353 & 3 & 3 \\
Yelwa & 10.83 & 4.73 & Midland & 142 & 2 & 2 \\
Bauchi & 10.37 & 9.80 & & 666 & 2 & 2 \\
Minna & 9.62 & 6.53 & & 258 & 3 & 3 \\
Jos & 9.92 & 8.95 & & 1219 & 3 & 3 \\
Yola & 9.23 & 12.47 & & 186 & 2 & 2 \\
Ibi & 8.18 & 9.75 & & 110 & 3 & 3 \\
Oshogbo & 7.78 & 7.03 & Guinea Savannah & 300 & 2 & 2 \\
Lokoja & 7.80 & 6.74 & & 151 & 2 & 2 \\
Ibadan & 7.43 & 3.70 & & 227 & 2 & 2 \\
Ikeja & 6.58 & 3.33 & Coastal & 39 & 2 & 2 \\
Enugu & 6.47 & 7.55 & & 141 & 3 & 3 \\
Warri & 5.52 & 5.73 & & 6 & 1 & 2 \\
Uyo & 5.05 & 7.93 & & 188 & 2 & 2 \\
\hline
\end{tabular}

\subsection{Conclusions}

A preliminary empirical assessment of wind impacts on sound level measurements over selected locations across Nigeria has been conducted for application in architectural acoustics. Significant wind impact was found for most of the stations with the exception of Warri thereby signaling the need for a detailed field survey where all the relevant parameters such as wind speeds, wind directions and noise levels are simultaneously measured to provide a valid experimental basis for the results obtained in these preliminary assessments. Meanwhile, the information presented highlights the importance of normalizing noise measurements as that will greatly impact on the accuracy of noise model calibration.

\section{References}

Abam, F. I. and Unwachukwu, C. O. (2009). Vehicular emission and air quality standards in Nigeria. European Journal of Scientific Research, 34, pp. 550-557.

Babisch, W., Beule, B., Schust, M., Kersten, N. and Ising, H. (2005). Traffic noise and risk of myocardial infarction. Epidemiology, 16(1), pp. 33-40.

Department of Transport, (1988). Calculation of road traffic noise (CRTN). The Stationery Office, London.

Designing Buildings Wiki, (2021). Building Acoustics. Online at www.designing buildings.co.uk [Accessed 16 Sept. 2021]

Diamant, R. M. E. (1986), Thermal and Acoustic Insulation, Butterworths, University press, Cambridge, United Kingdom.

Gilani, T. A. and Mir, M. S. (2021). Modelling road traffic noise under heterogeneous traffic conditions using the graph-theoretic approach. Environmental Science and Pollution Research, 28, pp. 36651-36668. https://doi.org/10.1007/s11356-021.13328-4.

Hadi Baaji, M., El-Fadel, M., Shazbak, S. M. and Saliby, E. (2001). Modeling noise at elevated highways in urban areas: A practical application. Journal of Urban Planning and Development, 127(4), pp. 169-180. https://doi.org/10.1061/(ASCE)0733-9488

Ighoroje, A. D. A., Marchie, C. and Nwobodo, E. D. (2004). Noise induced hearing impairement as an occupational risk factor among Nigerian traders. Nigerian Journal of Physiological Sciences, 19(1-2), pp. 14-19. 
Lihoreau, B., Gauvreau, B., Berengier, M., Blanc-Benon, P. and Calmet, I. (2006). Outdoor sound propagation modeling in realistic environments: Application of coupled parabolic and atmospheric models. Journal of Acoustical Society of America, 120, pp. 110-119.

Müller, G. and Möser, M. (2013). Handbook of Engineering Acoustics. Springer-Verlag Berlin Heidelberg. https://doi,org/ 10.1007/978-3-540-69460-1_2.

Ocholi, M. and Iheonu, E. E. (2011). Determination of Utilizable Wind Energy For Indoor Ventilation in Buildings across selected locations in Nigeria. Journal of the Nigerian Association of Mathematical Physics, 19, pp. 543-550.

Onuu, M. U. (1999). Statistics of road traffic noise. Global Journal of Pure and Applied Sciences, 5(4), pp. 571-575.

Onuu, M. U. and Menkiti, A. I. (1996). Analysis of Nigerian community response to road traffic noise. Journal of Science, Engineering and Technology, 3, pp. 536-547.

Ovenden, N. C., Shaffer, S. R. and Fernando, H. J. S. (2009). Impact of meteorological conditions on noise propagation from freeway corridors. Journal of the Acoustical Society of America, 126(1), pp. 25-35. https://doi.org/10.1121/1.3129125.

Ramakrishna, V., Saigiri, N., Chakribabu, K., Sultana, S. and Dhanunjay, M. (2021). Modeling and prediction of traffic noise levels. IOSR Journal of Engineering, 11(1), pp. 04-13.

Road Noise Group: Danish Environmental Protection Agency, Ministry of Finance, Ministry of Transport, Ministry of the Interior and Health, Ministry of Justice, Ministry of Economic and Business Affairs, (2003). Proposal of a strategy to reduce road noise traffic. http://www.eng.mst.dk. [Accessed Sept. 2021]

Rudolf, W. H. (1991). Field evaluation of acoustical performance of parallel highway noise barriers along Route 99 in Sacramento, Report No. FHWA/CA/TL-91/01, California Department of Transportation, Division of New Technology and Research, Sacramento, CA.

Rudolf, W. H. (2003). Additional calibration of traffic noise prediction models. Technical Advisory, Noise TAN-03-01 Final. California Department of Transportation, Division of New Technology and Research, Sacramento, CA.

Seidler, A., Wagner, M., Schubert, M., Droge, P., Romer, K., et al. (2016). Aircraft, railway and road traffic noise as risk factors for heart failure and hypertensive heart disease- a case control study based on secondary data. International Journal of Hygiene and Environmental Health, 219 (8), pp. 749-758. https://doi.org/10-1016/j.ijheh.2016.09.012.

Srimanta, G. and Chitralekha, G. (2011). Environmental noise assessment and its effect on human health in an urban area. International Journal of Environmental Sciences, 1(7), pp. 1954 - 1964.

Steele, C. (2001). A critical review of some traffic noise prediction models. Applied Acoustics, 62(3), pp. 271-287.

Technical Noise Supplement (TeNS) (1998). A technical supplement to the traffic noise analysis protocol. California Department of transportation, Environmental Program, Noise Air Quality, and Hazardous Waste Management Office.

Towseef, A. G. and Mohammad, S. M. (2021). Modelling road traffic noise under heterogeneous traffic conditions using the graph-theoretic approach. Environmental Science and Pollution Research, 28, pp. 36651-36668. 
Trikootam, S. C. and Hornikx, M., (2019). The wind effect on sound propagation over urban areas: Experimental approach with an uncontrolled sound source. Building and Environment, 149, pp. 561570.

Wayson, R. L., Martin, M., Edwards, A. M. and Wasko, R. (1995). The AAMA traffic noise modelA better approach," SAE Transaction: Journal of Passengers Cars, Part 2, 104, pp. 2402-2410.

\section{Appendix}

(MATLAB code used for calculating $\Delta d B, V_{m p}$ and $T$ )

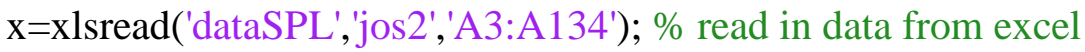

$\mathrm{n}=$ length $(\mathrm{x})$;

$\mathrm{x}=\operatorname{sort}(\mathrm{x})$;

$\mathrm{p}=((1: \mathrm{n})-0.5)^{\prime} . / \mathrm{n} ; \%$ computes the empirical cummulative distribution function ECDF

stairs(x,p,'k-');

xlabel('x');

ylabel('Cumulative probability (p)');

\%To fit a Weibull distribution to these data, notice that the CDF for the Weibull is $p=\operatorname{Pr}\{\mathrm{X}$ $<=\mathrm{x}\}=1-\exp \left(-(\mathrm{x} / \mathrm{a})^{\wedge} \mathrm{b}\right)$. Transforming that to $\log (\mathrm{a})+\log (-\log (1-\mathrm{p}))^{*}(1 / \mathrm{b})=\log (\mathrm{x})$ again gives a linear relationship, this time between $\log (-\log (1-\mathrm{p}))$ and $\log (\mathrm{x})$. We can use least squares to fit a straight line on the transformed scale using $\mathrm{p}$ and $\mathrm{x}$ from the ECDF, and the slope and intercept of that line lead to estimates of $a$ and $b$.

$\log \mathrm{x}=\log (\mathrm{x})$;

$\log y=\log (-\log (1-p))$;

poly $=$ polyfit $(\log y, \log x, 1)$;

paramHat $=[\exp (\operatorname{poly}(2)) 1 / \operatorname{poly}(1)]$;

$\%$ Plot the data and the fitted line on the transformed scale.

figure,

plot $\left(\log x, \log y,{ }^{\prime}+', \log (\right.$ paramHat(1)) + logy/paramHat(2),logy,'r--');

xlabel $\left(' \log (\mathrm{x})^{\prime}\right)$;

ylabel(' $\left.\log (-\log (1-\mathrm{p}))^{\prime}\right)$;

$\mathrm{Za}=2$;

$\mathrm{e}=(0.37-0.088 * \log (\operatorname{paramHat}(2))) /(1-0.088 * \log (\mathrm{Za} / 10))$;

param $1=$ paramHat $(1)^{*}(1-0.088 * \log (\mathrm{Za} / 10))^{\wedge}(-1)$;

param $2=$ paramHat $(2)^{*}(10 / \mathrm{Za})^{\wedge}(-\mathrm{e})$;

avgspeed=param $2 *$ gamma $(1+(1 /$ param 1$))$;

mpspeed $=$ param $2 *((\text { param } 1-1) / \text { param } 1)^{\wedge}(1 /$ param 1$)$;

fractionaltime $=\exp \left(-(\mathrm{mpspeed} / \text { param } 2)^{\wedge}\right.$ param 1$)$;

dbdiff $=3+\log (\mathrm{mpspeed} / 5)$;

\section{Cite this article as:}

Ocholi M., Ibe K. E., Iheonu E. E. and Ameh E. E., 2021. Assessing Wind Impact on Noise Level Measurements for Application in Architectural Acoustics: A Preliminary Study. Nigerian Journal of Environmental Sciences and Technology, 5(2), pp. 413-419. https://doi.org/10.36263/nijest.2021.02.0290 